Angew Chem Int Ed Engl. 2016 November 02; 55(45): 14077-14080. doi:10.1002/anie.201608446.

\title{
Regiodivergent and Diastereoselective CuH-Catalyzed Allylation of Imines from Terminal Allenes
}

\author{
Richard Y. Liu, Dr Yang Yang, and Prof. Dr. Stephen L. Buchwald \\ Department of Chemistry, Massachusetts Institute of Technology, 77 Massachusetts Avenue, \\ Cambridge, MA 02139 (USA)
}

\begin{abstract}
A copper-catalyzed, chemoselective hydrometalation process enables the use of simple allenes as allylmetal nucleophile surrogates in imine allylation reactions. By modulation of the nitrogenprotecting group, either highly branched- or linear-selective addition can be achieved from the same allene. Both reactions exhibit excellent diastereoselectivity and broad functional group tolerance. Preliminary results indicate that good enantioselectivity can also be achieved in the linear-selective reaction. Finally, a mechanistic model for the regiodivergence is proposed on the basis of density functional theory calculations.
\end{abstract}

\section{Graphical Abstract}

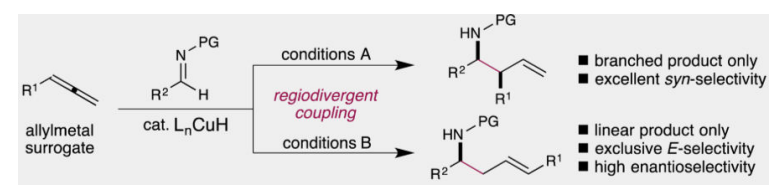

\begin{abstract}
A copper-hydride catalyst enables the synthesis of valuable homoallylic amines by chemoselective hydrocupration of easily accessible allenes, followed by coupling with imines. Two complementary sets of conditions are developed that yield purely the branched or linear isomer of the amine products. Each operates at ambient temperature, tolerates a range of polar functional groups, and proceeds with high diastereoselectivity.
\end{abstract}

\section{Keywords}

amines; copper; C-C coupling; multicomponent reactions; regioselectivity

The prevalence of nitrogen-substituted fragments in biologically active molecules has motivated the development of numerous efficient methods for their construction. ${ }^{[1]}$ Among these, the catalytic synthesis of homoallylic amines from stereoselective addition of an allyl fragment to imines has been the subject of extensive investigation. ${ }^{[2]}$ Typically, these approaches require stoichiometric quantities of an allylmetal reagent as the nucleophilic component. ${ }^{[3,4,5]}$ Thus, control of the stereoselectivity (syn vs. anti, $E$ vs. $Z$ ) and regioselectivity (linear vs. branched) of the allylation reaction demands the highly regio- and 
diastereoselective synthesis of the corresponding precursor. Although elegant solutions exist for simple nucleophiles, the synthesis of more complex reagents, especially those containing base-sensitive functional groups, remains challenging. ${ }^{[6]}$ As an alternative, we considered the possibility of catalytic access to both regioisomers from a common, easily prepared allyl nucleophile surrogate. ${ }^{[7]}$

Our group and others have investigated the generation of organocopper intermediates through the reaction of catalytic copper hydride with unsaturated substrates. ${ }^{[8,9]}$ When these species are generated in a chemoselective manner in the presence of a suitable electrophile, functional group-tolerant, stereoselective $\mathrm{C}-\mathrm{C}^{[8]}$ or $\mathrm{C}-$ heteroatom ${ }^{[9]}$ bond formation can be achieved. In particular, we have recently described copper-catalyzed reductive addition reactions of olefin-derived nucleophiles to carbonyl and imine electrophiles. ${ }^{[8 a, b, f]}$ Using other metals, several elegant methods for the generation of allylmetal nucleophiles from boro- ${ }^{[7 \mathrm{a}, \mathrm{b}]}$ carbo- ${ }^{[7 \mathrm{f}, \mathrm{g}, \mathrm{h}]}$ or hydrometalation ${ }^{[7 \mathrm{c}, \mathrm{d}, \mathrm{e}]}$ of allenes or 1,3-dienes have been the subject of recent publications. We envisioned that a new hydrocupration-nucleophilic attack strategy to effect stereo- and regiocontrolled allylation of imines would represent a valuable addition to the existing collection of $\mathrm{CuH}$-catalyzed $\mathrm{C}-\mathrm{C}$ bond-forming transformations.

Specifically, as shown in Figure 1B, we proposed that hydrocupration of readily available ${ }^{[10]}$ terminal allenes might enable catalytic formation of chiral allylcopper complexes. We reasoned that subsequent addition of the allylcopper intermediate into imines, followed by ligand exchange with an alcohol ${ }^{[8 \mathrm{a}, 8 \mathrm{e}, 11]}$ could afford either regioisomer of the homoallylic amine and a copper alkoxide species. Subsequent $\sigma$-bond metathesis with a hydrosilane would then regenerate the copper hydride and close the catalytic cycle. In this manuscript, we describe the development of complementary systems for synthesis of the branched and linear regioisomers of homoallylic amines with high diastereoselectivity.

We initiated our development of these reactions by examining the reaction of cyclohexylallene with a number of simple $N$-protected imine electrophiles under copper hydride catalysis conditions. With 1,2-bis(dicyclohexylphosphino)ethane (DCyPE) as the supporting ligand, allylation of $\mathrm{N}$-benzyl imines was observed in high yield, generating branched product with excellent regioselectivity. Diastereoselectivity was sensitive to solvent, with the use of MTBE providing the highest syn:anti ratio (Table 1, entries 1-4). Replacement of the benzyl group with 2,4-dimethoxybenzyl (DMB) led to further improvement of the diastereoselectivity (entry 6).

At this point, we considered whether other $N$-protecting groups, especially those potentially favoring different coordination modes, could alter the regiochemical outcome of this reaction (Table 1, entries 7-10). The effect of these modifications was most profound in the case of the diphenylphosphinoyl (DPP) group, which overturned the observed regioisomer preference to exclusively linear with excellent selectivity for the $E$-olefin (Table 1, entry 10). Importantly, the amine protecting groups identified for either regioselective protocol (DMB and DPP) can be cleaved under mildly acidic conditions. ${ }^{[12]}$

The two sets of conditions established above were next evaluated for their scope in terms of compatible reaction partners. For the branched-selective reaction (Table 2), imines spanning 
a range of electronic properties could be transformed with high $s y n$-selectivity $(\mathbf{6 a}-\mathbf{6 c})$.

Heterocyclic imines were also suitable reactants (6d-6f), with the heteroaryl bromide group remaining intact under the reaction conditions. An aliphatic imine could be allylated as well, although selectivity for the syn diastereomer was modest in this instance (6k). For this imine, use of the parent benzyl protecting group resulted in better reactivity than the DMB group in terms of reactivity. This strategy was also employed for other less reactive imines, including ortho-substituted pyrazole $\mathbf{6 d}$. Terminal allene substrates bearing various functional groups were also suitable for this protocol, including ones containing an ester (6h), a sulfonamide (6i), and a secondary amide (6j). Finally, branched-selective allylation conditions can also provide near-quantitative yields of reverse prenylation (6l) and protected syn-1,2-aminoalcohol (6m) products.

Using the second set of conditions, the linear homoallylic amines were obtained with excellent regioselectivity and high selectivity for the (E)-alkene geometry (Table 3). Again, aldimines bearing both electron-rich and electron-poor (hetero)aryl groups (7a-7f) could be utilized. Unbranched allenes were also suitable substrates for this reaction $\mathbf{7 g})$, and polar functional groups such as an ester (7h), a sulfonamide (7i), and an amide (7j) could also be employed, without any detrimental effect on regioselectivity or geometric purity. In all of these linear-selective reactions, no undesired branched regioisomer was observed, and only trace amounts of the $Z$-alkene product was produced in a few instances.

During the course of our optimization, we found that chiral ligand $\mathrm{Ph}-\mathrm{BPE}$ promoted the linear-selective reaction with high efficiency. When enantiomerically pure ligand was used, promising levels of enantioselectivity could be obtained under improved conditions (Figure 2). ${ }^{[13]}$ In this case, the crystallinity of $N$-DPP amines proved to be advantageous: following linear allylation, a small amount of nearly racemic product could be separated from the crude reaction as a solid following a single crystallization from ethyl acetate-hexanes, leaving behind more enantioenriched material. X-ray diffraction analysis of (-)-7a confirmed the connectivity and absolute configuration. With additional optimization, highly enantioselective versions of these allylation conditions might be achieved to further enhance the utility of these already highly diastereo-, regio- and chemoselective transformations.

Aiming to elucidate the mechanistic basis for the observed regiodivergence, we performed density functional theory (DFT) calculations on the reaction of DCyPE-ligated copper hydride with allenes and imines (Figure 3). Calculations suggest that irreversible hydrocupration of an allene forms a mixture of allylcopper species that quickly equilibrates to form the thermodynamically favored terminal $(E)$-allyl copper intermediate as the predominant species (see Supporting Information for details). In the case of $N$-phosphinoyl imine electrophiles, we found that an allylation transition state structure involving copper coordination to oxygen is favored over alternative open or $N$-bound geometries (Figure 3A). Transfer of the allyl fragment through the copper-bound carbon atom results in the linear product. In contrast, for $N$-benzyl imines, the only closed transition state structure involves copper coordination to the imine nitrogen (Figure 3B). This six-membered, chair-like transition state leads to transfer of the allyl fragment through the internal carbon, leading to the branched product.

Angew Chem Int Ed Engl. Author manuscript; available in PMC 2017 November 02. 
In summary, a new copper-catalyzed regiodivergent allylation reaction of imines has been developed. Using simple allenes as allyl nucleophile surrogates, either linear or branched homoallylic amines can be obtained with high stereoselectivity. Further efforts towards the catalytic generation of organometallic nucleophiles from alkenes for selective bond-forming reactions are ongoing.

\section{Supplementary Material}

Refer to Web version on PubMed Central for supplementary material.

\section{Acknowledgments}

Research reported in this publication was supported by the National Institutes of Health (GM46059, GM058160-17S1). R.Y.L. thanks MIT for a Presidential Graduate Fellowship. We are grateful to Dr. Peter Mueller for X-ray crystallographic analysis and to Drs. Yi-Ming Wang, Mycah Uehling, and Christine Nguyen for advice on the preparation of this manuscript.

\section{References}

1. Ricci, A. Amino Group Chemistry: from Synthesis to the Life Sciences. Weinheim, Germany: Wiley $\mathrm{VCH} ; 2010$.

2. For selected reviews on stereoselective allylation of imine compounds or related reactions, see: Huo H-X, Duvall JR, Huang M-Y, Hong R. Org. Chem. Front. 2014; 1:303. Wisniewska HM, Jarvo ER. J. Org. Chem. 2013; 78:11629. [PubMed: 24266761] Yus M, González-Gómez J, Foubelo F. Chem. Rev. 2011; 111:7774. [PubMed: 21923136] Kobayashi S, Mori Y, Fossey JS, Salter MM. Chem. Rev. 2011; 111:2626. [PubMed: 21405021] Friestad GK, Mathies AK. Tetrahedron. 2007; 63:2541. Kobayashi S, Ishitani H. Chem. Rev. 1999; 99:1069. [PubMed: 11749440]

3. For examples of catalytic, stereoselective addition of allylmetal reagents to imines, see: Silverio DL, Torker S, Pilyugina T, Vieira EM, Snapper ML, Haeffner F, Hoveyda AH. Nature. 2013; 494:216. [PubMed: 23407537] Vieira EM, Snapper ML, Hoveyda AH. J. Am. Chem. Soc. 2011; 133:3332. [PubMed: 21341657] Fujita M, Nagano T, Schneider U, Hamada T, Ogawa C, Kobayashi S. J. Am. Chem. Soc. 2008; 130:2914. [PubMed: 18278917] Wada R, Shibuguchi T, Makino S, Oisaki K, Kanai M, Shibasaki M. J. Am. Chem. Soc. 2006; 128:7687. [PubMed: 16756326] Fernandes RA, Yamamoto Y. J. Org. Chem. 2004; 69:735. [PubMed: 14750798] Ferraris D, Dudding T, Young B, Drury WJ, Lectka T. J. Org. Chem. 1999; 64:2168. Nakamura H, Nakamura K, Yamamoto Y. J. Am. Chem. Soc. 1998; 120:4242.

4. Catalytic, stereoselective addition of electrophilic allyl reagents to imines using metal reductant is also known, see: Chakrabarti A, Konishi H, Yamaguchi M, Schneider U, Kobayashi S. Angew. Chem. Int. Ed. 2010; 49:1838. Takahashi M, McLaughlin M, Micalizio GC. Angew. Chem. Int. Ed. 2009; 48:3648. Tan KL, Jacobsen EN. Angew. Chem. Int. Ed. 2007; 46:1315.

5. Several imine allylation methods relying on reagent or auxiliary control of stereochemistry are important synthetically. For selected examples, see: Robak MT, Herbage MA, Ellman JA. Chem. Rev. 2010; 110:3600. [PubMed: 20420386] Huber JD, Leighton JL. J. Am. Chem. Soc. 2007; 129:14552. [PubMed: 17983233] Canales E, Hernandez E, Soderquist JA. J. Am. Chem. Soc. 2006; 128:8712. [PubMed: 16819848] Berger R, Duff K, Leighton JL. J. Am. Chem. Soc. 2004; 126:5686. [PubMed: 15125659] Job A, Janeck CF, Bettray W, Peters R, Enders D. Tetrahedron. 2002; 58:2253.

6. For representative methods for the preparation of crotyl, prenyl, or substituted cinnamyl nucleophiles, see: Huber JD, Perl NR, Leighton JL. Angew. Chem. Int. Ed. 2008; 47:3037. Brown HC, Jadhav PK. Tetrahedron Lett. 1984; 25:1215. Schlosser M, Rauchschwalbe G. J. Am. Chem. Soc. 1978; 100:3258.

7. For representative examples of metal-catalyzed imine allylation methods circumvent the use of stoichiometric allylmetal reagents, see: Yeung K, Ruscoe RE, Rae J, Pulis AP, Procter DJ. Angew. Chem. Int. Ed. 2016; 55:1102. Rae J, Yeung K, McDouall JJW, Procter DJ. Angew. Chem. Int. Ed. 
2016; 55:1102. Oda S, Franke J, Krische MJ. Chem. Sci. 2016; 7:136. Oda S, Sam B, Krische MJ. Angew. Chem. Int. Ed. 2015; 54:8525. Chen T-Y, Tsutsumi R, Montgomery TP, Volchkov I, Krische MJ. J. Am. Chem. Soc. 2015; 137:1798. [PubMed: 25642996] Tran DN, Cramer N. Angew. Chem. Int. Ed. 2010; 49:8181. Hopkins CD, Malinakova HC. Org. Lett. 2006; 8:5971. [PubMed: 17165907] Cooper IR, Grigg R, MacLachlan WS, Thronton-Pett M, Visuvanathar S. Chem. Commun. 2002:1372.

8. a) Yang Y, Perry IB, Buchwald SL. J. Am. Chem. Soc. 2016; 138:9787. [PubMed: 27454393] b) Yang Y, Perry IB, Lu G, Liu P, Buchwald SL. Science. 2016; 353:144. [PubMed: 27284169] c) Wang Y-M, Buchwald SL. J. Am. Chem. Soc. 2016; 138:5024. [PubMed: 27042864] d) Bandar JS, Ascic E, Buchwald SL. J. Am. Chem. Soc. 2016; 138:5821. [PubMed: 27121395] e) Ascic E, Buchwald SL. J. Am. Chem. Soc. 2015; 137:4666. [PubMed: 25826004] f) Wang Y-M, Bruno NC, Placeres AL, Zhu S, Buchwald SL. J. Am. Chem. Soc. 2015; 137:10524. [PubMed: 26256576] g) Suess AM, Uehling MR, Kaminsky W, Lalic G. J. Am. Chem. Soc. 2015; 137:7747. [PubMed: 26042355] h) Uehling MR, Suess AM, Lalic G. J. Am. Chem. Soc. 2015; 137:1424. [PubMed: 25621888]

9. For a review, see: Wang Y-M, Pirnot MT, Buchwald SL. Angew. Chem. Int. Ed. 2016; 55:48. Some related methods were studied contemporaneously by others, see: Xi Y, Butcher TW, Zhang J, Hartwig JF. Angew. Chem. Int. Ed. 2016; 55:776. Nishikawa D, Hirano K, Miura M. J. Am. Chem. Soc. 2015; 137:15620. [PubMed: 26653275] Miki Y, Hirano K, Satoh T, Miura M. Angew. Chem. Int. Ed. 2013; 52:10830. Noh D, Chea H, Ju J, Yun J. Angew. Chem. Int. Ed. 2009; 48:6062.

10. Terminal allenes are easily prepared from terminal alkynes, see: Kuang J, Ma S. J. Org. Chem. 2009; 74:1763. [PubMed: 19123833] Searles S, Li Y, Nassim B, Lopes M-TR, Tran PT, Crabbé P. J. Chem. Soc., Perkin Trans. 1. 1984:747.

11. For the effect of alcohol additives in CuH catalysis, see: Hughes G, Kimura M, Buchwald SL. J. Am. Chem. Soc. 2003; 125:11253. [PubMed: 16220945]

12. a) Ramage R, Hopton D, Parrott MJ, Keener GW, Moore GA. J. Chem. Soc., Perkin Trans. 1. 1984:1357.b) Park C-MJ. Org. Chem. 2006; 71:413.

13. In contrast, evaluation of compatible chiral ligands for the branched-selective reaction has not provided above $11 \%$ ee. This is consistent with our theoretical studies on the enantiodetermining addition step, and further studies are being conducted towards achieving an enantioselective branched-selective reaction.

14. M06/6-311+G(d,p)-SDD/SMD(THF)//B3LYP/6-31G(d)-SDD plus a harmonic vibrational correction at $298 \mathrm{~K}$. Further details and results can be found in the Supporting Information. 
A Cu-catalyzed regiodivergent allylation of imines using terminal allenes

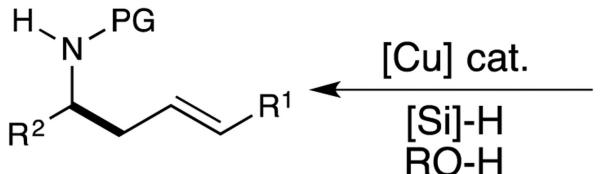

linear product

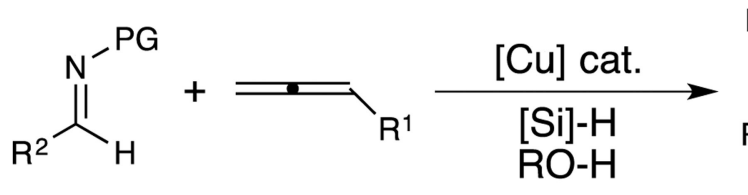

allene<smiles>[R7]C(C=C)C([R7])NP</smiles>
branched product

B Postulated reaction mechanism

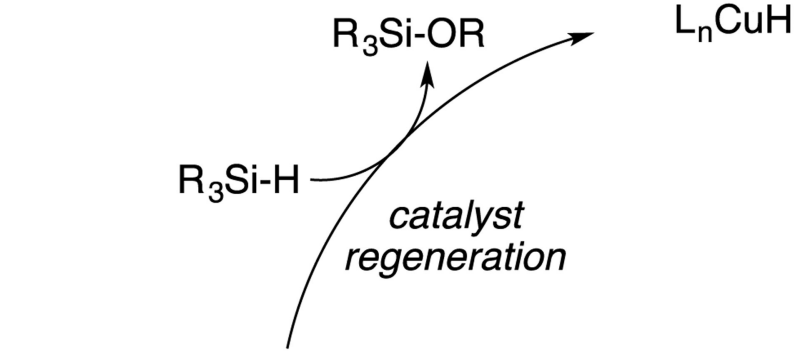
CuH-Catalyzed
Imine Allylation

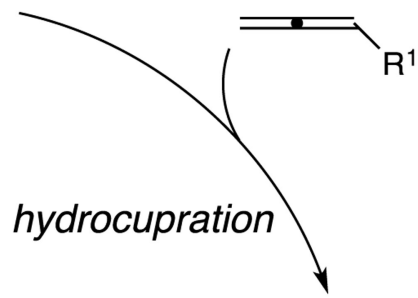

catalytic generation of allylmetal nucleophile

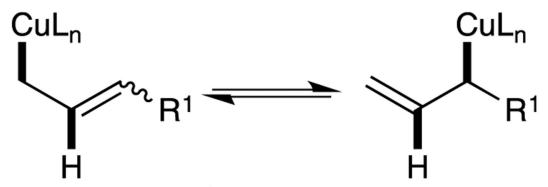

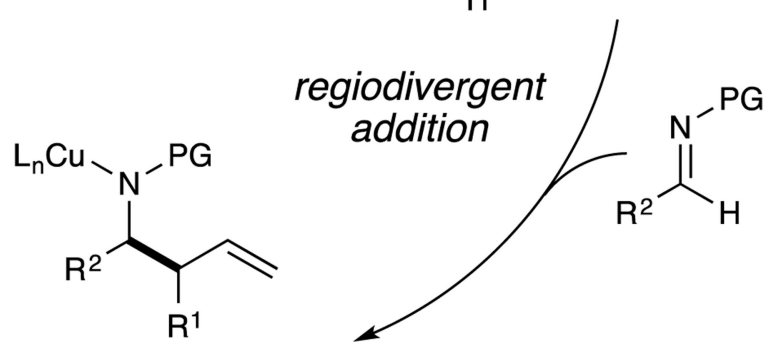<smiles>[R]OCCI</smiles>

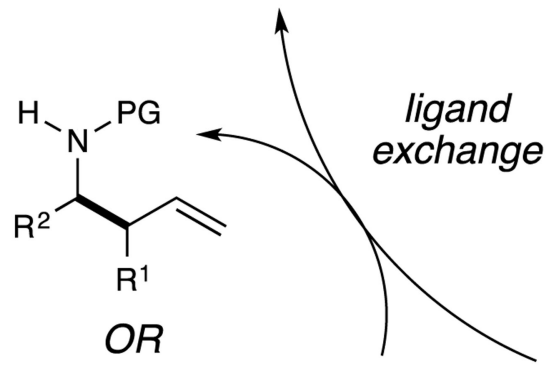<smiles>N[PbH2]</smiles>
$\mathrm{RO}-\mathrm{H}$<smiles>[R7]C=CCC([R2])N(C)C</smiles>

$O R$<smiles>[14CH3]N[TeH]</smiles><smiles>[R7]C=CCC([Y9])[R7]</smiles>

\section{Principal challenges}

- Chemoselectivity: hydrocupration of $\mathrm{C}=\mathrm{C}$ bond in the presence of $\mathrm{C}=\mathrm{N}$ bond

- Regioselectivity: access to both branched and linear products

- Diastereoselectivity: syn/anti in branched products; $E / Z$ in linear products

Figure 1.

Overview of the $\mathrm{CuH}$-catalyzed reductive allylation reaction of imines using allenes. 


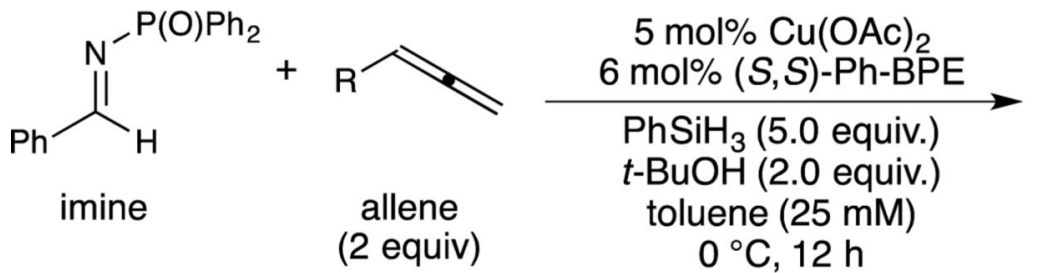<smiles></smiles><smiles>c1ccc(C2CC[C@@H](c3ccccc3)P2CCP2[C@H](c3ccccc3)CC[PH2+]2c2ccccc2)cc1</smiles>

$(S, S)-\mathrm{Ph}-\mathrm{BPE}$
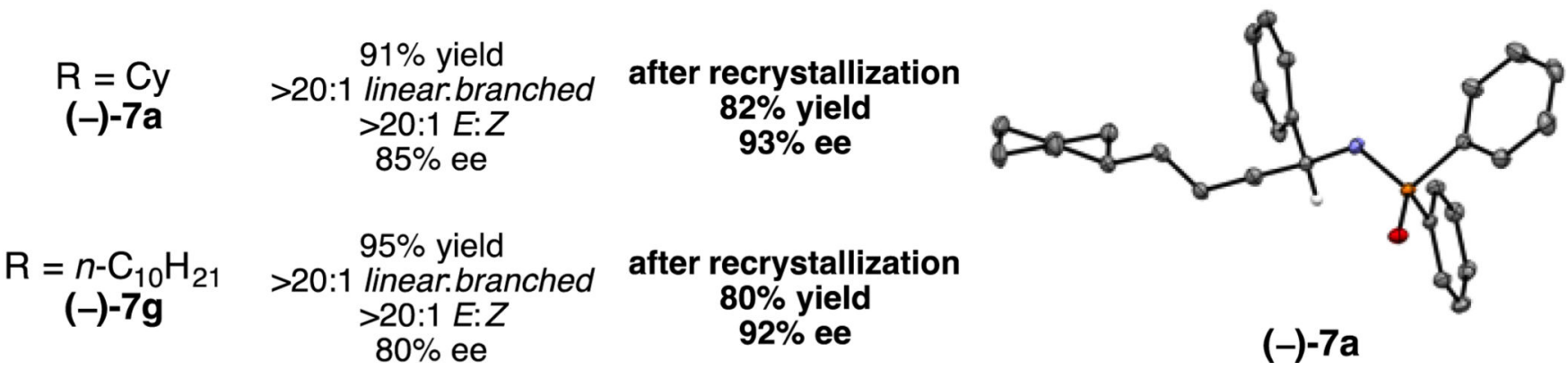

$(-)-7 a$

Figure 2.

Enantioselective variant of linear-selective allylation reaction. 
A Linear-selective reaction TS
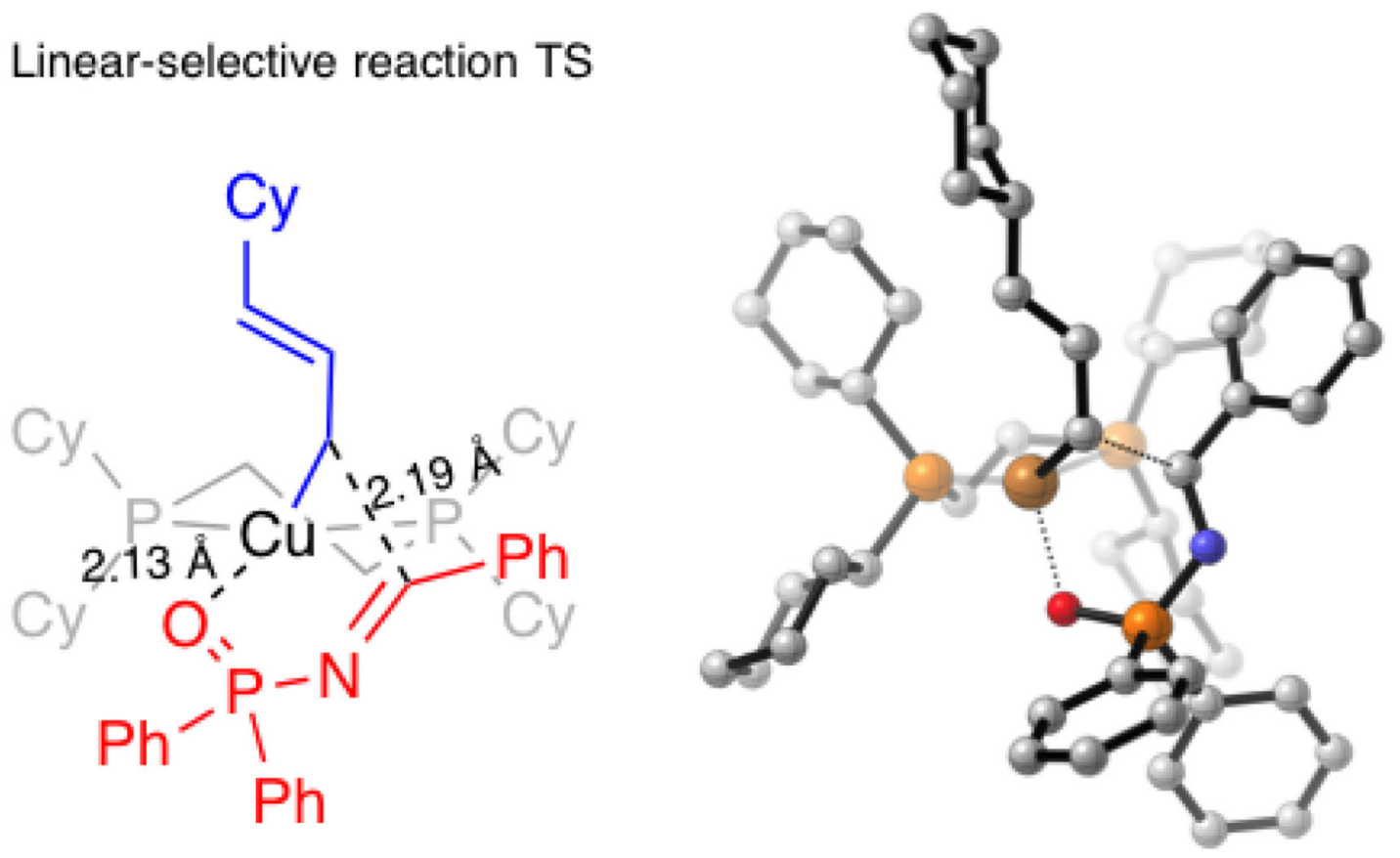

B Branched-selective reaction TS

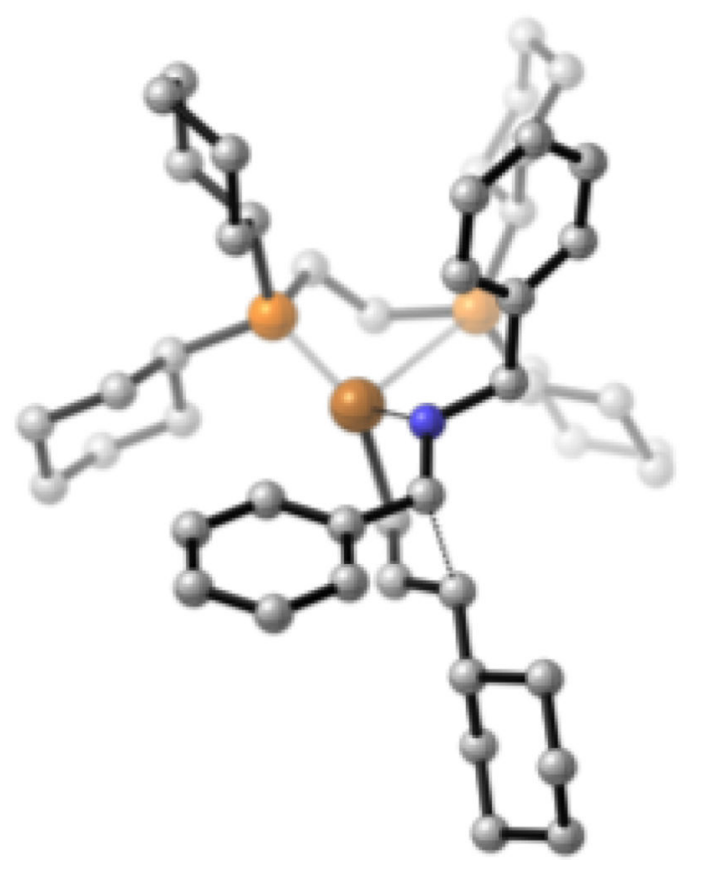

Figure 3.

DFT transition state models of regiodivergence in copper-catalyzed allylation reactions. ${ }^{[14]}$ 


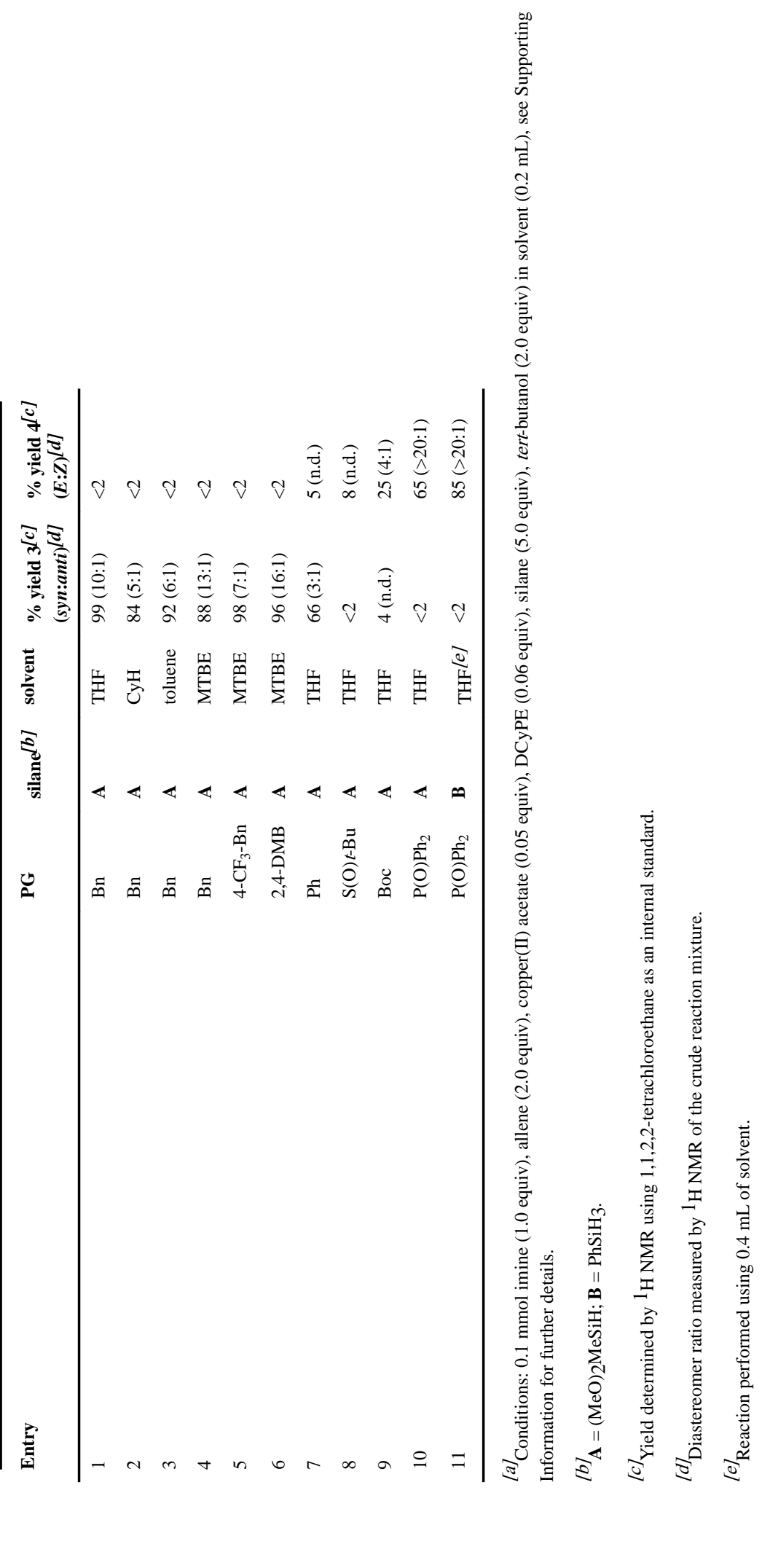

Angew Chem Int Ed Engl. Author manuscript; available in PMC 2017 November 02. 
Table 2

Scope of Branched-Selective Allylation Reaction. [a,b,c]

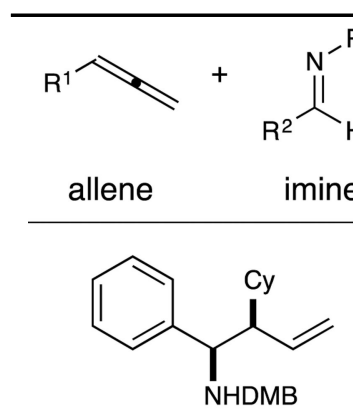

$6 a$

$95 \%$ yield

>20:1 branched:linear

16:1 syn:anti<smiles>C=CC(Cc1ccccc1)C(N)c1cn(C)nc1C</smiles>

6d

$79 \%$ yield

>20:1 branched:linear

10:1 syn:anti

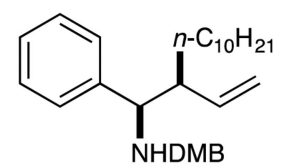

6g

$89 \%$ yield

>20:1 branched:linear 19:1 syn:anti

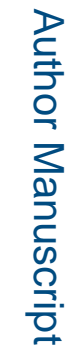

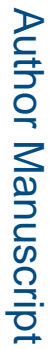<smiles>C=CC(CCCCCCCc1ccccc1)[C@@H](N)C1CCCCC1</smiles>

$6 \mathrm{k}$

$48 \%$ yield

$>20: 1$ branched:linear

$$
\text { 2:1 syn:anti }
$$

${ }^{\text {[a] }} \mathrm{Co}$

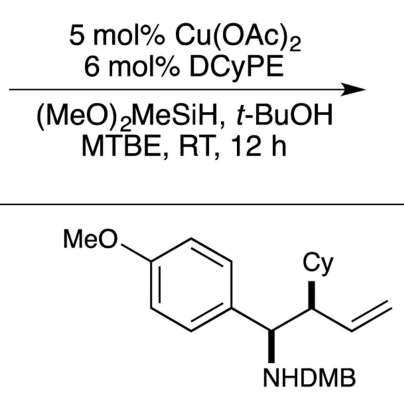

6b

$97 \%$ yield

$>20: 1$ branched: linear $>20: 1$ syn:anti<smiles>C=CC(Cl)C(NOC(C)(C)C)c1ccc(Br)s1</smiles>

$6 e$

$65 \%$ yield >20:1 branched:linear 15:1 syn:anti<smiles>[X]CCCC(C=C)C(N)c1ccccc1</smiles>

6h (X=OPiv)

$72 \%$ yield

>20:1 branched:linear

9:1 syn:anti

$6 i$ (X=NMeTs)

$69 \%$ yield

$>20: 1$ branched:linear

8:1 syn:anti<smiles>C=CC(C)(C)C(NOC(C)(C)C)c1ccccc1</smiles>

61

$99 \%$ yield >20:1 branched:linear<smiles>[R]C(C=C)C([R])NC</smiles>

NHDMB

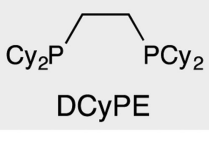<smiles>C=C[C@H](NC(C)(C)C)[C@H](NC(C)(C)C)c1ccc(C(F)(F)F)cc1</smiles>

$6 c$

$98 \%$ yield

$>20: 1$ branched:linear

9:1 syn:anti<smiles>C=CC(C1CCCCC1)[C@H](NCCC)c1ccc(OC)nc1</smiles>

$6 f$

$77 \%$ yield

>20:1 branched:linear

14:1 syn:anti<smiles>C=C[C@H](CCC(=O)NCc1ccccc1)[C@H](NC(C)(C)C)c1ccccc1</smiles>

6j

$71 \%$ yield

>20:1 branched:linear

12:1 syn:anti butanol (2.0 equiv) in MTBE ( 1.0 or $2.0 \mathrm{~mL}$ ), see Supporting Information for further details.

${ }^{[b]}$ Average isolated yield from two experiments. 
${ }^{[c]}$ Diastereomer ratio measured by ${ }^{1} \mathrm{H}$ NMR of the crude reaction mixture. 
Table 3

Scope of Linear-Selective Allylation Reaction. [ $\left.{ }^{a, b, c}\right]$

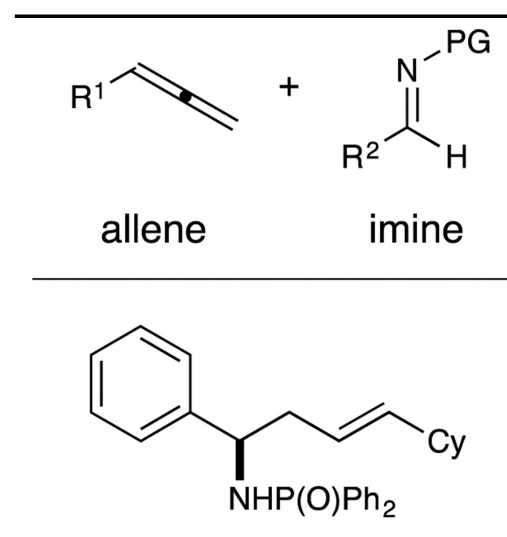

$7 a$

$80 \%$ yield

$>20: 1$ linear.branched

$>20: 1 \mathrm{E:} Z$<smiles>OP=PNC(C/C=C/C1CCCCC1)c1ccc(Br)s1</smiles>

$7 e$

$85 \%$ yield

$>20: 1$ linear.branched

$>20: 1 \mathrm{E:} Z$

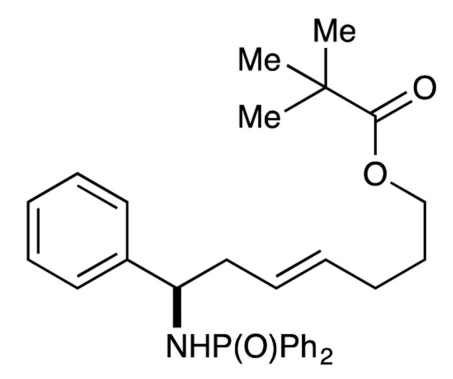

7h

$90 \%$ yield

$>20: 1$ linear.branched $>20: 1 E: Z$

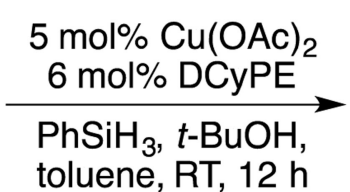

toluene, RT, $12 \mathrm{~h}$<smiles>COc1ccc(C(C/C=C/C2CCCCC2)NPc2ccccc2)cc1</smiles>

$7 \mathbf{b}$

$92 \%$ yield

$>20: 1$ linear.branched

$>20: 1 E: Z$<smiles>[CH]/C=C/C[C@H](NPc1ccccc1)c1ccc(OC)nc1</smiles>

$7 f$

$92 \%$ yield

$>20: 1$ linear.branched

$>20: 1 E: Z$

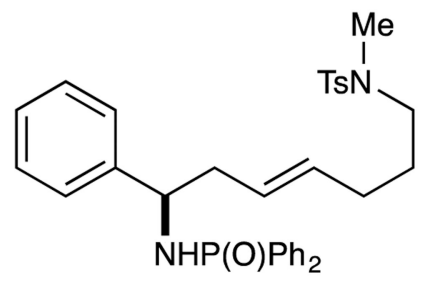

$7 \mathbf{i}$

$81 \%$ yield

$>20: 1$ linear.branched

$>20: 1 E: Z$<smiles>[R]C=CCC([R])N[Po]</smiles>

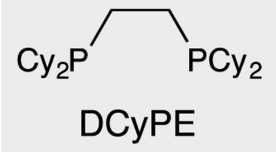

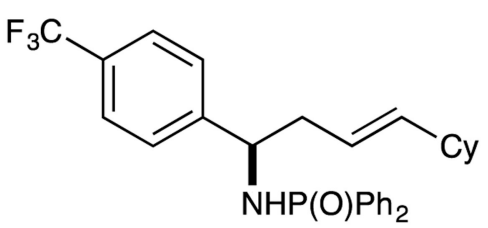

$7 c$

$69 \%$ yield $>20: 1$ linear.branched $>20: 1 E: Z$

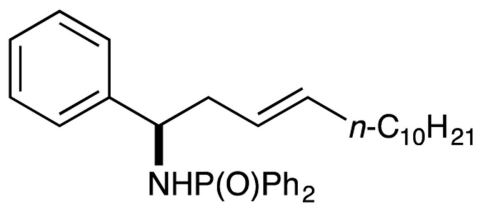

$7 \mathrm{~g}$

95\% yield $>20: 1$ linear.branched $>20: 1 \mathrm{E}: Z$<smiles>O=C(CC/C=C/C[C@H](Nc1ccccc1)c1ccccc1)NCc1ccccc1</smiles>

$7 \mathbf{j}$

$55 \%$ yield

$>20: 1$ linear.branched $>20: 1 \mathrm{E}: Z$

${ }^{[a]}$ Conditions: $0.5 \mathrm{mmol}$ imine (1.0 equiv), allene (2.0 equiv), copper(II) acetate ( 0.05 equiv), DCyPE ( 0.06 equiv), phenylsilane (5.0 equiv), tertbutanol (2.0 equiv) in toluene ( $4.0 \mathrm{~mL})$, see Supporting Information for further details.

${ }^{[b]}$ Average isolated yield from two experiments. 
${ }^{[c]}$ Diastereomer ratio measured by ${ }^{1} \mathrm{H}$ NMR of the crude reaction mixture. 